\title{
A Comparison of Two Fire Field Models with Experimental Room Fire Data
}

\author{
L. KERRISON, N. MAWHINNEY, E. R. GALEA', N. HOFFMANN and M. K. PATEL \\ Fire Safety Engineering Group \\ Centre For Numerical Modelling and Process Analysis \\ The University of Greenwich \\ London SE18 6PF. U.K.
}

\begin{abstract}
This paper describes the application of two fire field models to the description of fire induced flows in domestic sized rooms. A systematic and critical comparison is made of two commonly used CFD codes for fire modelling, PHOENICS and FLOW3D. Comparisons are based on upper-layer room temperatures, mass fluxes in and out of the fire compartment and door-way vertical and horizontal temperature and velocity profiles. Given identical meshes, both models agree reasonably well with the observed trends. A close examination of the horizontal door-way velocity profiles highlights the need for careful modelling and experimental practices.
\end{abstract}

KEYWORDS Compartment fires, Field models, FLOW3D, PHOENICS, CFD.

\section{INTRODUCTION}

Over the past 10 years considerable effort has been expended in developing field models capable of predicting the development of hazardous conditions within fire enclosures [1-4]. At the heart of these fire field models is the Computational Fluid Dynamics (CFD) code and a large proportion of these models are based on commercial CFD software such as PHOENICS [5] and FLOW3D [6]. The former is the core of the JASMINE [7] code and an aircraft cabin fire code [3] while the latter has been used to investigate the Kings Cross Underground fire [2] as well as aircraft [8] and high rise building fire scenarios [8].

While most specialist fire field models are compared with specialist experimental data, little effort has been invested in the systematic comparison of these models or their core software with common experimental data. This is due, for the most part, to the lack of suitable experimental benchmark fire data. The majority of fire experiments are not conducted for model validation purposes and a significant number of those that are, are specifically designed for the validation of the less demanding zonal models. In most of these cases insufficient data is recorded to allow a detailed 'validation' of field models.

1 author to whom enquires should be directed 
The thorough 'validation' of fire field models demands considerable thought and precision from both the modeller and experimenter. The modeller must accurately specify the geometry and the relevant physics/chemistry as well as take into consideration numerical aspects relating to the operation of the software. The experimenter must not only make accurate and relevant measurements but must also precisely position the measuring devices. The 'validation' process is a non-trivial task as even the simplest steady-state field model typically involves in excess of 40,000 degrees of freedom. A thorough validation would require each degree of freedom to be compared with a corresponding measurement. Clearly, this is not practical and so in practice any validation exercise involves a series of compromises.

In this paper a comparison is made of two commonly used CFD codes for fire modelling, PHOENICS and FLOW3D. The ability of the codes to model a series of room fire experiments [9] is examined and further comparisons are made with earlier published studies produced using the JASMINE code [10] and a code produced by the National Fire Laboratory of Canada [11].

\section{THE EXPERIMENTS:}

A series of 45 experiments were conducted by Steckler et al [9] to investigate fire induced flows in a compartment measuring $2.8 \mathrm{~m} \mathrm{X} 2.8 \mathrm{~m}$ in plan and $2.18 \mathrm{~m}$ in height. The walls were $0.1 \mathrm{~m}$ thick and the walls and ceiling were covered with a light-weight ceramic fibre insulation board. The series of experiments consisted of a gas burner placed systematically in 8 different floor locations with a variety of single compartment openings ranging from small windows to wide doors. The $0.3 \mathrm{~m}$ diameter bumer was supplied with commercial grade methane at a fixed rate producing constant fire strengths of $31.6,62.9,105.3$ and $158 \mathrm{~kW}$. Near steady-state conditions were achieved within 30 minutes.

An array of bi-directional velocity probes and bare-wire thermocouples were placed within the room opening to measure velocities and temperatures within the centre of the door jamb. In addition, a stack of aspirated thermocouples were placed in the front comer of the room to measure the gas temperature profile.

\section{NUMERICAL SIMULATIONS:}

A number of simulations were performed based on five fire locations, three door widths and two fire sizes $[12,13]$. Here, the results for the $62.9 \mathrm{~kW}$ centre fire location will be reported. By considering the heat convected out of the room it is estimated that typically $3 \mathrm{~kW}$ of heat is lost to the walls and through the effects of radiation. In the numerical model, the heat release rate is adjusted to take account of this figure. The door openings used in these simulations measured $1.83 \mathrm{~m}$ in height and $0.24,0.74$ and $0.99 \mathrm{~m}$ in width. The simulations were performed using both the PHOENICS (V 1.6) and FLOW3D (V 2.3.3) software.

The starting point of the analysis is the set of three-dimensional, partial differential equations that govern the phenomena of interest here. This set consists, in general, of the following equations: the continuity equation; the three momentum equations that govern the conservation of momentum per unit mass in each of the three space dimensions; the equation for conservation of energy; and, the equations for a turbulence model, in this case the k- 
epsilon model with buoyancy modifications. The precise formulation of the differential equations describing the model will not be given here as they may be found elsewhere $[6,7,14]$. Combustion and radiation are ignored in the simulations presented here.

The initial temperature was set to the experimentally measured ambient temperature while the INSULATING walls of the compartment were modelled with no-slip conditions for the velocities and adiabatic conditions for the temperature. The usual 'wall functions' [15] were used to compute shear stresses at the wall. In order to correctly model the flow through the open door, the numerical grid was extended by $1.4 \mathrm{~m}$ to include a region outside the fire compartment. A fixed pressure boundary condition was used on all external boundaries.

A mesh of 8280 cells in total was used to discritise the geometry (6480 internal and 1800 external cells). The mesh consisted of 23 cells in length, 20 cells in width and 18 cells in height. This mesh was used by both codes however, the FLOW3D model requires 2 additional non-participating dummy cells in each direction in order to facilitate the boundary conditions. The mesh was non-uniformly distributed with refinements in the wall, floor, ceiling, fire and doorway regions.

FLOW3D was run in transient mode, typically requiring 200 time steps before reaching steady-state conditions. Within each time step, convergence was assumed if either the maximum number of iterations (100) was reached or the mass source residual fell to $1 \times 10^{-04}$. Steady-state is considered to be achieved when the maximum change between spot values falls to less than $1 \%$ between time steps.

The PHOENICS code was run in steady-state mode, typically requiring 1000 sweeps to achieve convergence. This was deemed to be attained when the mass imbalance fell to below $1 \times 10^{-04}$, residuals fell to less than $1 \%$ of average variable values and spot values differed by less than $0.1 \%$. Both codes used the hybrid differencing scheme throughout however different linear equation solvers were used in each code.

The primary purpose of this work is to provide a basis of comparison for two CFD codes which are frequently used for fire field modelling applications. For this reason, boundary conditions and problem specification have been kept deliberately simple, ensuring that the problem specification is identical in both cases while also being a reasonable approximation to the experiment. Studies investigating the effects of radiation and boundary conditions are the subject of a later publication.

\section{RESULTS AND DISCUSSION:}

The gross features observed in the experiment have been captured by both codes (see table 1). As the door width is increased from $0.24 \mathrm{~m}$ to $0.99 \mathrm{~m}$, the height of the neutral plane is observed to increase. Throughout the simulations, both codes have tended to underestimate the location of the neutral plane by similar amounts. This is to be expected as both codes used identical meshes and the accuracy of the neutral plane location is constrained by the mesh resolution within the doorway.

Similarly, as the door width increases the mass flow rates into and out of the fire compartment increase. Here the two codes again produce similar results with FLOW3D being 
on average within $5 \%$ while PHOENICS being within $9 \%$ of the measured values. For the $0.74 \mathrm{~m}$ door, FLOW3D predicts the in- and out-mass flow rates to be within 5\% and $4 \%$ respectively of the measured values, while the corresponding PHOENICS results are within $7 \%$ and $4 \%$. The results reported for a similar model (without radiation) using the JASMINE code [10] - on a slightly coarser mesh (6270 cells) - are within $8 \%$ and $11 \%$ respectively.

The average upper layer temperature decreases with increasing door width. This temperature was determined experimentally by averaging the temperature values in the upper layer as measured by the thermocouple stack located in the corner of the room. In table 1, two upper layer temperatures are presented for each case, the 'stack' value represents a mean temperature determined in a similar manner to the experimental values while the 'plane' values are a mean value over an entire plane $1.8 \mathrm{~m}$ above the floor. Once again the two codes produce similar results with FLOW3D being on average within $15 \%$ while PHOENICS being within $16 \%$ of the measured values.

TABLE 1. Comparison of FLOW3D and PHOENICS predictions of Neutral Plane Height, Mass Flow Rates and Upper Layer Temperature with experimental results as a function of door width.

\begin{tabular}{|c|c|c|c|c|c|c|}
\hline & \multicolumn{6}{|c|}{ DOOR WITHS } \\
\hline & \multicolumn{2}{|c|}{$0.24 \mathrm{~m}$} & \multicolumn{2}{|c|}{$0.74 \mathrm{~m}$} & \multicolumn{2}{|c|}{$0.99 \mathrm{~m}$} \\
\hline $\begin{array}{l}\text { Neutral Plane Height (m) } \\
\text { FLOW3D }\end{array}$ & \multicolumn{2}{|c|}{0.866} & \multicolumn{2}{|c|}{0.926} & \multicolumn{2}{|c|}{1.020} \\
\hline $\begin{array}{c}\text { Neutral Plane Height (m) } \\
\text { PHOENICS }\end{array}$ & \multicolumn{2}{|c|}{0.866} & \multicolumn{2}{|c|}{0.922} & \multicolumn{2}{|c|}{0.937} \\
\hline $\begin{array}{c}\text { Neutral Plane Height (m) } \\
\text { EXPERIMENT }\end{array}$ & \multicolumn{2}{|c|}{0.912} & \multicolumn{2}{|c|}{1.027} & \multicolumn{2}{|c|}{1.065} \\
\hline $\begin{array}{c}\text { Mass Flow Rates (kg/sec) } \\
\text { FLOW3D }\end{array}$ & $\begin{array}{c}\text { IN } \\
0.248\end{array}$ & $\begin{array}{l}\text { OUT } \\
0.252\end{array}$ & $\begin{array}{c}\text { IN } \\
0.582\end{array}$ & $\begin{array}{l}\text { OUT } \\
0.591\end{array}$ & $\begin{array}{c}\text { IN } \\
0.716\end{array}$ & $\begin{array}{l}\text { OUT } \\
0.722\end{array}$ \\
\hline $\begin{array}{c}\text { Mass Flow Rates }(\mathrm{kg} / \mathrm{sec}) \\
\text { PHOENICS }\end{array}$ & 0.290 & 0.290 & 0.597 & 0.597 & 0.710 & 0.711 \\
\hline $\begin{array}{c}\text { Mass Flow Rates }(\mathrm{kg} / \mathrm{sec}) \\
\text { EXPERIMENT }\end{array}$ & 0.255 & 0.247 & 0.554 & 0.571 & 0.653 & 0.701 \\
\hline $\begin{array}{c}\text { Hot Layer Temp (C) } \\
\text { FLOW3D }\end{array}$ & $\begin{array}{c}\text { plane } \\
231\end{array}$ & $\begin{array}{l}\text { stack } \\
267\end{array}$ & $\begin{array}{c}\text { plane } \\
128\end{array}$ & $\begin{array}{l}\text { stack } \\
134\end{array}$ & $\begin{array}{c}\text { plane } \\
103\end{array}$ & $\begin{array}{c}\text { stack } \\
108\end{array}$ \\
\hline $\begin{array}{l}\text { Hot Layer Temp (C) } \\
\text { PHOENCIS }\end{array}$ & 244 & 245 & 141 & 141 & 119 & 119 \\
\hline $\begin{array}{l}\text { Hot Layer Temp (C) } \\
\text { EXPERIMENT }\end{array}$ & \multicolumn{2}{|c|}{190} & \multicolumn{2}{|c|}{129} & \multicolumn{2}{|c|}{109} \\
\hline
\end{tabular}




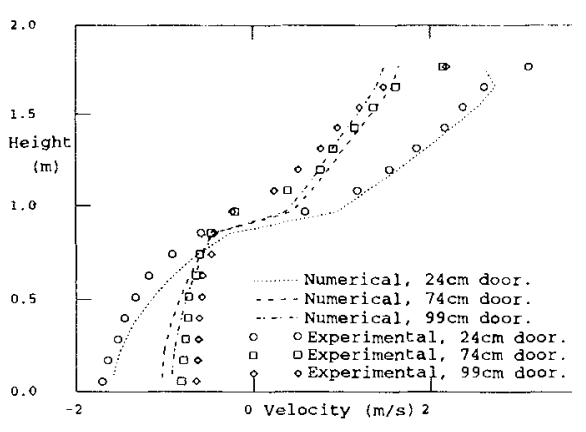

$1 \mathrm{~A}$

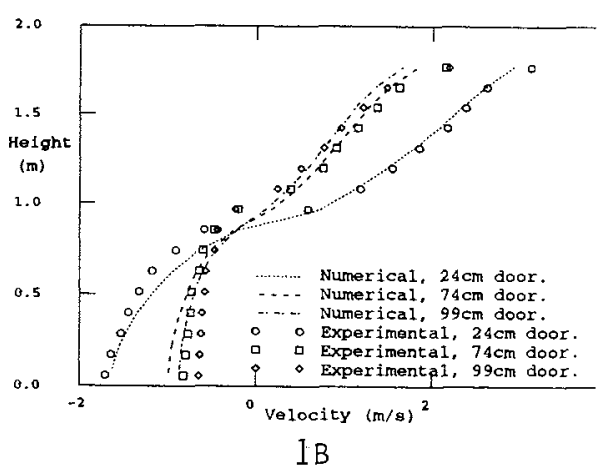

FIGURE 1. Experimental and numerical vertical velocity profiles in the centre of the doorway for $0.24 \mathrm{~m}, 0.74 \mathrm{~m}$ and $0.99 \mathrm{~m}$ wide doors produced by the FLOW3D (1a) and PHOENICS models (1b).
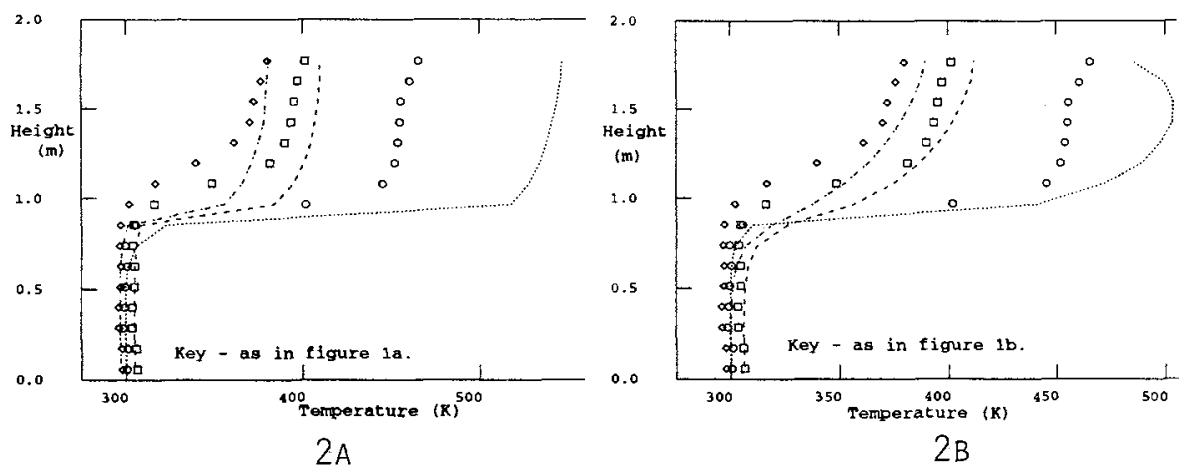

FIGURE 2. Experimental and numerical vertical temperature profiles in the centre of the doorway for $0.24 \mathrm{~m}, 0.74 \mathrm{~m}$ and $0.99 \mathrm{~m}$ wide doors produced by the FLOW3D (2a) and PHOENICS models (2b). 


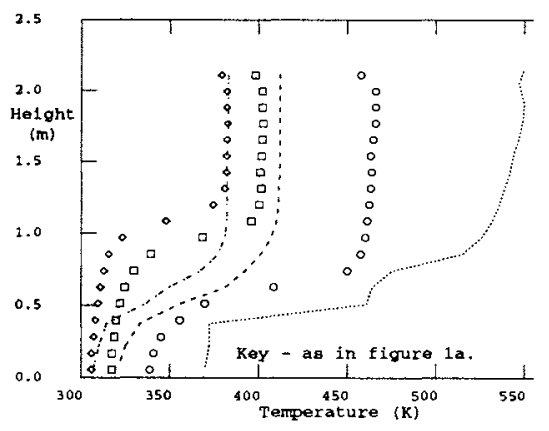

$3 A$

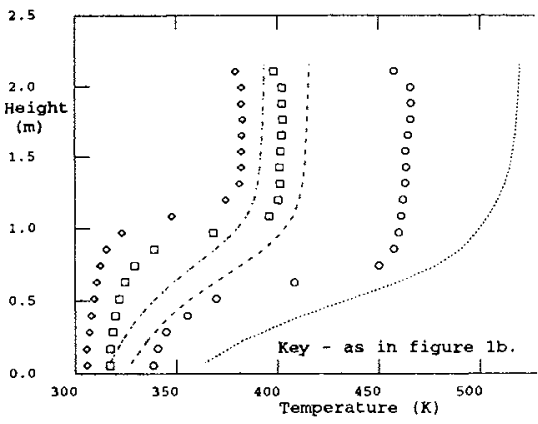

3B

FIGURE 3. Measured and predicted vertical temperature profiles in the room corner for $0.24 \mathrm{~m}, 0.74 \mathrm{~m}$ and $0.99 \mathrm{~m}$ wide doors produced by the FLOW3D (3a) and PHOENICS (3b) models.
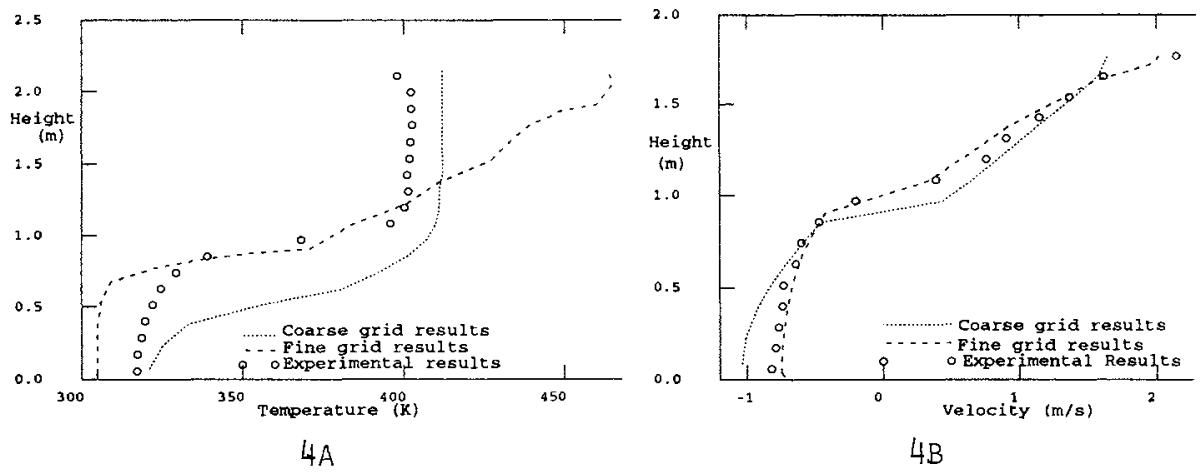

FIGURE 4. Comparison of measured and predicted doorway vertical temperature (4a) and velocity (4b) profiles using the fine and coarse comutational mesh. Results for the $0.74 \mathrm{~m}$ wide door are depicted. 
Predictions of doorway centreline velocities as a function of door width are depicted in figure 1 for the FLOW3D code (figure 1a) and the PHOENICS code (figure 1b). Both codesproduce good agreement with experimental data, however they both tend to under-predict velocities in the upper most portion of the door. This behaviour was also reported in the JASMINE predictions [10] all-be-it for a different case and by Hadjisophocleous [11].

Further mesh refinement produces an appreciable improvement in the overall level of agreement (see figure $4 \mathrm{~b}$ ), however the maximum velocity is still under-predicted. The accuracy of the experimental results in this region are questionable. In order to achieve meaningful results, the bi-directional velocity probes must be aligned parallel to the velocity streamlines. The velocity probes in the experiment were placed with their axes horizontal ie parallel to the floor. However, in the vicinity of the door edges - particularly the top edge where the hot buoyant gases exit the room - the streamlines intercept the door plane at acute angles leading to the possibility of substantial measurement errors.

Predictions of doorway centreline temperatures as a function of door width are depicted in figure 2 for the FLOW3D (figure 2a) and PHOENICS codes (figure 2b). Both codes produce reasonable agreement with experimental data and are capable of predicting the observed trends as door widths decrease. Of the two codes, FLOW3D appears to be more successful at predicting the cold and hot layer temperatures. Both codes appear to have greatest difficulty with the narrow door case, PHOENICS over-predicting the upper-layer temperature by some $47^{\circ} \mathrm{C}(26 \%)$ and FLOW3D by $80^{\circ} \mathrm{C}(40 \%)$. This is probably due to poor mesh refinement in the narrow door case as only 2 cells were used across the width of the door compared with 8 cells in the wide door case. However, in all cases, both codes fail to accurately predict the sharp transition between the hot and cold layers. This could be due to substantial smearing due to false diffusion resulting from the use of the upwind scheme, inadequacies in the turbulence model and/or the lack of a radiation model.

The poorest level of overall agreement was observed for the corner stack temperatures (figure 3 ). With the exception of the narrow door case, both codes provide a good approximation to the upper layer temperatures. However, they tend to over-predict the lower layer temperatures and fail to predict the transition between hot and cold layers. PHOENICS (figure $3 \mathrm{~b}$ ) in particular has severely smeared the temperature profile in the lower regions.

A possible explanation for the difference between the FLOW3D and PHOENICS results concerns the treatment of wall boundary conditions. As the measuring station is located close to the confining walls, the boundary conditions will have a significant effect on the temperature profile. While identical wall boundary conditions were specified in each code, their internal implementation may be different. Furthermore, the difference between the numerical results and the experimental data is possibly due to the simple nature of the wall boundary condition specification.

In addition, the overall level of mesh refinement will influence the degree to which both codes agree with the experimental data. For the FLOW3D results it was noted that while coarser meshes revealed similar overall flow features to those produced on the 8280 cell mesh, suggesting mesh independence, a significant mesh refinement to 45,356 cells (exploiting geometry symmetry) [12] reveals considerable improvements in the agreement with the measured results for some of the profiles (figure 4). 
The degree to which the fire plume is deflected backwards by the induced incoming flow can be seen in figure 5 for the $0.74 \mathrm{~m}$ door. While it is extremely difficult to make accurate measurements, the inclination of the FLOW3D (figure 5a) produced plume - at approximately $70^{\circ}$ to the horizontal - appears to be less pronounced than the $45^{\circ}$ suggested by the PHOENICS (figure 5b) results. The PHOENICS result appears to agree more closely with the observations of Quintiere et al [16] in an earlier series of experiments. Using an identical experimental setup, they observed the flame angle for this case to lie between $33^{\circ}$ and $43^{\circ}$.

A significant observation to emerge from the experimental work concerned the nature of the horizontal velocity distribution within the door jamb. In most of the cases, the velocity profile was observed to peak at the door edges with a minimum in the middle. Steckler et al [17] have argued that these results are consistent with potential flow theory if the flow is assumed to be irrotational and inviscid. However, in their JASMINE simulation, Kumar et al [10] noted completely the opposite result, ie peak velocities were predicted in the centre of the door. Similar trends were also noted by Hadjisophocleous [11]. In the JASMINE simulation, the door wall appears to have been modelled through the use of a thin surface.

Using this approach, the high faces of the last cells within the room are closed off thereby defining a soffit and door jamb of zero thickness. As PHOENICS uses a staggered velocity mesh, velocity vectors are located at the cell faces in line with the zero thickness soffit (see figure 6a). However, the pressures which are used to determine the velocity are obtained from the neighbouring cell centres located just outside and inside the fire compartment. In most applications this is a fair approximation, however if detailed comparisons with experimental data derived from within the door jamb are required then this may prove too crude an approximation.

To gauge the significance of this approximation, a series of simulations were performed using the PHOENICS code in which the soffit was modelled as a thin surface of zero thickness, a single cell $0.1 \mathrm{~m}$ thick and two cells measuring $0.05 \mathrm{~m}$ each. The case presented here relates to the $31.6 \mathrm{kw}$ central fire with $0.74 \mathrm{~m}$ door.

With two cells defining the door soffit three velocities are produced within the door jamb, one at its centre, one at its inside edge and another at its outside edge (see figure 6b). All three velocities have at least one driving pressure point located within the door jamb.

Figure 7 depicts horizontal velocity profiles at $1.66 \mathrm{~m}$ above the floor for the experiment, the thin surface soffit representation and the two cell soffit at the inside edge, centre and outside edge locations. The experimental velocity curve peaks towards the door edges producing a concave profile. The thin surface soffit curve is virtually flat with a slight decrease at the edges. This is similar to the velocity profile in the centre of the two cell soffit, however in this case there appears to be a greater down turn towards the door edges. The velocity profile at the inside edge of the jamb agrees most closely with the trends revealed in the experiment producing a concave profile while the profile at the outside edge appears inverted with the velocity attaining minimum values towards the door edges.

Clearly, a velocity gradient exists through the thickness of the door jamb which is impossible to detect by a thin surface representation of the soffit. If a two cell soffit representation is used, the numerical velocity profile matches the measured profile but its location appears to be displaced by as much as $0.05 \mathrm{~m}$ towards the inside edge of the jamb. 


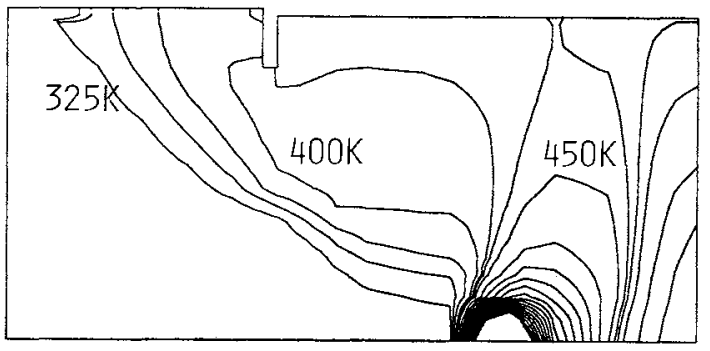

$5 ; A$

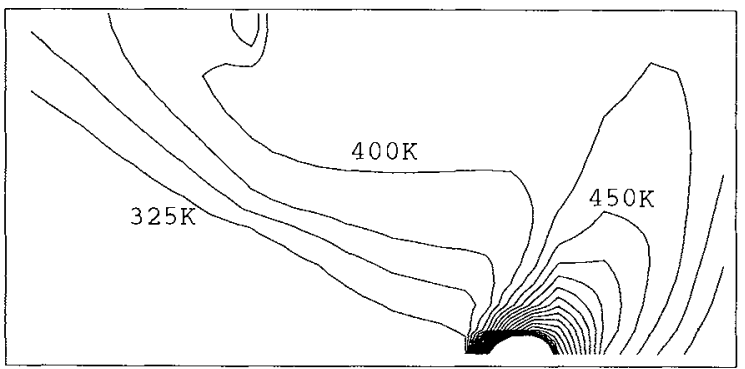

$5 \mathrm{~B}$

FIGURE 5. Comparison of FLOW3D (5a) and PHOENICS (5b) predicted temperature distributions through the centre of the fire compartment passing through the centre of the door ( $0.74 \mathrm{~m}$ wide).
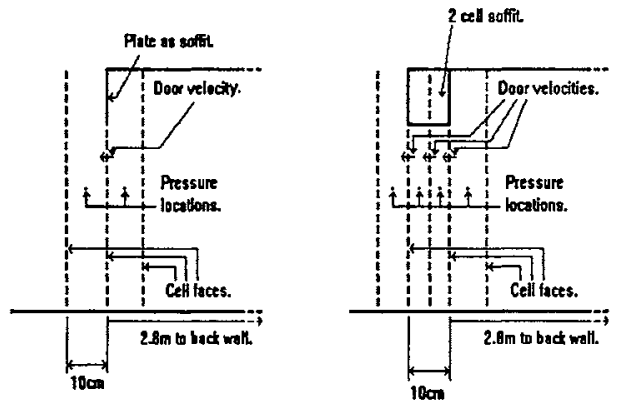

FIGURE 6. Velocity and pressure locations within doorway for PHOENICS models describing soffit as a zero thickness plate and a two cell thick soffit. 
With regard to the experimental results there are two issues concerning their accuracy which need to be considered. First, as mentioned above, the velocity measurements in the vicinity of the door edges are prone to large errors if the bi-directional probes are not aligned parallel to the flow. Secondly, the velocity probes function by converting a measured pressure difference across a small but finite distance - typically of the order of $0.02 \mathrm{~m}$ - into a velocity. As the door jamb is $0.1 \mathrm{~m}$ thick, the exact positioning of the probe becomes crucial if detailed comparisons with field models are to be attempted.

There appear to be no significant differences in the vertical velocity profile located in the centre of the door for the plate, single cell and two cell soffit representation [12]. However, the mass fluxes in and out of the compartment have changed from $0.500 \mathrm{~kg} / \mathrm{sec}$ (for both cases) as determined by the plate soffit to $0.551 \mathrm{~kg} / \mathrm{sec}$ (for both cases) for the two cell soffit, an increase of $10 \%$. The experimental values were $0.461 \mathrm{~kg} / \mathrm{sec}$ out and $0.430 \mathrm{~kg} / \mathrm{sec}$ in. While the shape of the temperature profiles has not altered, the value for the upper layer temperatures within the centre of the door and in the stack have decreased by about $8^{\circ} \mathrm{C}$, bringing them within $5^{\circ} \mathrm{C}$ of the measured temperatures. This decrease is to be expected as the mass flux out of the room has increased.

Finally, consider the numerical efficiency of the two software packages. Both the PHOENICS and FLOW3D software were run on a $40 \mathrm{Mhz}$ SUN SPARC 10 workstation rated at 13.7 MFLOPS on the standard LINPACK benchmark. A typical transient simulation using the FLOW3D software required $26.26 \mathrm{hrs}$ of CPU, while the equivalent steady-state PHOENICS simulation required $1.63 \mathrm{hrs}$.

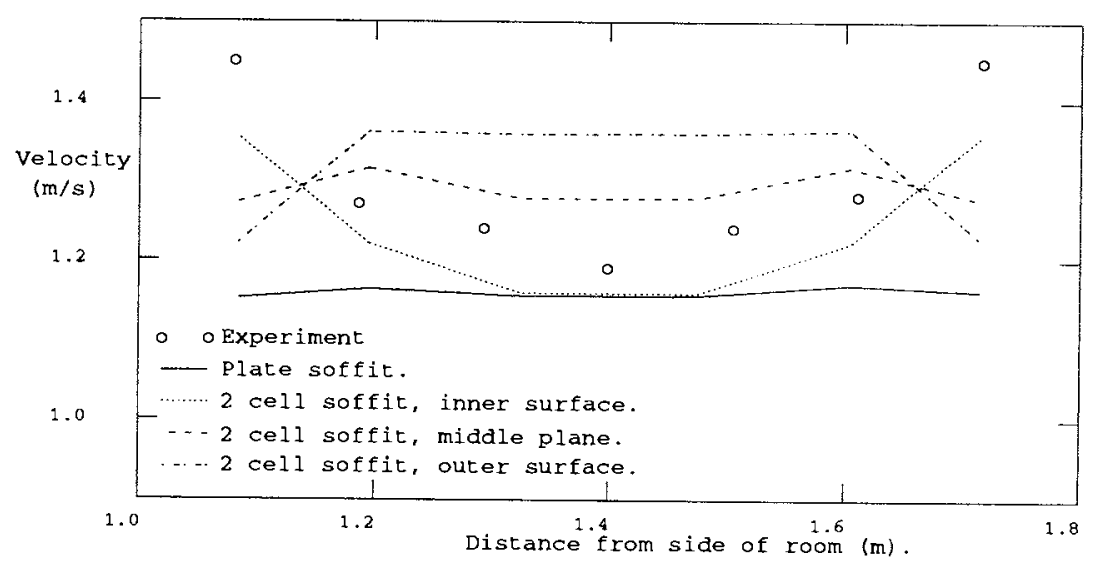

FIGURE 7. Measured and predicted horizontal velocity distribution at various locations within the doorway for the plate and two cell thick soffit. 
As is to be expected, the transient simulations require considerably more effort than the corresponding steady-state simulations. However, in order to gauge the efficiency of each code it is necessary to normalise the CPU time by the amount of work performed. This is determined by considering the number of cells and iterations involved in each of the calculations. Each case involves a total of 8280 cells, and the FLOW3D simulations typically required 200 time steps with a maximum of 100 outer and 30 inner iterations resulting in $1.9 \times 10^{-05} \mathrm{cpu}-\mathrm{sec} / \mathrm{cell} /$ time step/iteration. The PHOENICS simulations typically involved a maximum of 1000 sweeps and 20 inner iterations, resulting in $3.5 \times 10^{-05} \mathrm{cpu}-$ $\mathrm{sec} / \mathrm{cell} / \mathrm{sweep} /$ iteration. This suggests that at most, FLOW3D is 1.8 times faster than PHOENICS in visiting each cell in the calculation.

\section{CONCLUSIONS}

Based on comparisons of upper-layer temperature, mass fluxes into and out of the compartment and neutral plane height, both the FLOW3D and PHOENICS models produced reasonable agreement with measured room fire data. The FLOW3D and PHOENICS predicted doorway vertical velocity and temperature profiles are also in good agreement with the measured profiles.

However, both models had difficulty predicting the corner temperature stratification with the PHOENICS model completely smearing the lower portion of the profile. The observed differences in performance between the two models are thought to be due to differing treatments of the wall boundary conditions. Considerable improvements in the FLOW3D results were achieved by significantly refining the computational mesh.

An investigation of the doorway horizontal velocity profile reveals that careful modelling of this region is essential in order to correctly predict measured trends. Furthermore, the predicted profile is sensitive to the exact location within the door jamb suggesting the need for extremely accurate experimental practices. Further work in fire model validation is currently underway.

\section{ACKNOWLEDGEMENTS}

Professor E Galea is indebted to the CAA for their financial support of his personal chair in Mathematical Modelling at the University of Greenwich. The authors are indebted to CHAM for allowing the use of PHOENICS and the UK AEA for allowing the use of FLOW3D while, L Kerrison acknowledges the SERC for finacial support and N Mawhinney acknowledges the SERC and the UK AEA for financial support.

\section{REFERENCES}

1. Galea E.R., "On the field modelling approach to the simulation of enclosure fires" J. Fire Protection Engng 1 (1), 11-22 1989.

2. Simcox S, Wilkes N,S and Jones I.P., "Fire at Kings Cross Underground Station, 18th November 1987; Numerical simulation of the buoyant flow and heat transfer", U.K. Atomic Energy Authority Harwell Report. 1988, AERE-G 4677. 
3. Galea E.R. and Markatos N.C., "The mathematical modelling and computer simulation of fire development in aircraft" Int.J.Heat Mass Transfer, 1991, Vol 34. No.1 pp 181-197

4. Markatos N.C. and Cox G., "Hydrodynamics and heat transfer in enclosures", PhysicoChem. Hydrody. 19845 (1), 53-66.

5. Spalding D.B, "A general purpose computer program for multi-dimensional one- and twophase flow", in Mathematics and Computers in Simulations, North Holland (IMACS), Vol XXIII, 1981, 267.

6. Burns A.D and Wilkes N.S, "A finite-difference method for the computation of fluid flows in complex 3-D geometries", U.K. Atomic Energy Authority Harwell Report. AERE-R 12342.

7. Markatos N.C, Malin M.R and Cox G., "Mathematical modelling of buoyancy induced smoke flow in enclosures" Int J heat Mass Transfer, 25 (1), 1982, 63.

8. Galea E.R, Hoffmann N and Berhane D., "Large-Scale Fire Field Modelling - the Route to General Use via Parallel Processing" Interflam'93, pub. by Interscience 1993, pp $307-319$.

9. Steckler K.D, Quintiere J.G and Rinkinen W.J., "Flow induced by Fire in a Compartment". NBSIR 82-2520, National Bureau of Standards, Washington, September 1982.

10. Kumar S, Gupta A.K and Cox G., "Effects of Thermal Radiation on the Fluid Dynamics of Compartment Fires". Fire Safety Science, Proc 3rd Int Symp, Ed: Cox G and Langford B, Elsevier Applied Science pp 345-354.

11. Hadjisophocleous G.V. and Cacambouras M., "Computer modeling of compartment fires", J. of Fire Prot. Engr., 5 (2), 39-52, 1993.

12. Kerrison L , Galea E.R, Hoffmann N and Patel M.K., "A Comparison of a FLOW3D based Fire Field Model with Experimental Room Fire Data". Submitted to Fire Safety Journal.

13. Mawhinney N, Galea E.R, Hoffmann N and Patel M.K., "A Comparison of a PHOENICS based Fire Field Model with Experimental Room Fire Data". In Preparation.

14. Patankar S.V, Numerical Heat Transfer and Fluid Flow. McGraw Hill, New York, USA, 1980.

15. Patankar S.V and Spalding D.B., "A calculation procedure for heat, mass and momentum transfer in three-dimensional parabolic flows". Int.J.Heat Mass Transfer, 15, 1972, 1787 1806.

16. Quintiere J.G, Rinkinen W.J and Jones W.W., "The Effect of Room openings on Fire Plume Entrainment". Combustion Science and Technology, 26, 1981, 193-201.

17. Steckler K.D, Baum H.R and Quintiere J.G, "Fire Induced Flows Through Room Openings - Flow Coefficients". Twentieth Symp on Combustion, The Combustion Inst. 1984, pp 1591-1600. 